$\xi=\mathrm{\alpha}$

\title{
Correlations of circulating levels of oxidants, antioxidants and soluble Fas in breast cancer among Egyptian females
}

\author{
Sayed H. Madboly ${ }^{1}$, Elsaeid M.E. Elbawab ${ }^{2}$, Abdallah M. A.A. El-Ebidi ${ }^{3}$, Omar A.E. Sayed ${ }^{4}$, \\ Mohammed H. Hassan ${ }^{5} *$ Tahia H. Saleem $^{6}$, Sameh S.E. Elsayed ${ }^{2}$ \\ ${ }^{I}$ Department of Medical Biochemistry and Molecular Biology, Faculty of Medicine, Al-Azhar University, Cairo, Egypt \\ ${ }^{2}$ Department of Medical Biochemistry and Molecular Biology, Faculty of Medicine, Al-Azhar University, Assiut, Egypt \\ ${ }^{3}$ Department of Medical Biochemistry and Molecular Biology, Faculty of Medicine, Aswan University, Egypt \\ ${ }^{4}$ Department of General Surgery, Faculty of Medicine, Sohag University, Egypt \\ ${ }^{5}$ Department of Medical Biochemistry and Molecular Biology, Qena Faculty of Medicine, South Valley University, Egypt \\ ${ }^{6}$ Department of Medical Biochemistry and Molecular Biology, Faculty of Medicine, Assiut University, Egypt \\ *Corresponding author E-mail:mohammedhosnyhassaan@yahoo.com
}

\begin{abstract}
Background: Breast cancer is the first most common malignancy in Egyptian females. Oxidative stress is considered to be involved in the pathophysiology of all cancers, especially breast cancer. An inappropriately low rate of apoptosis can give rise to cancer.

Objectives: The purpose of this study was to asses, compare and correlate the circulatory levels of some oxidants (malondialdehyde "MDA" and nitric oxide "NO"), total antioxidant capacity "TAO") and soluble form of Fas "sFas" in some Egyptian females having breast cancer.

Methods: A cross sectional case/control study conducted on 50 Egyptian females recruited from outpatient clinics or inpatients department of the general surgery at Sohag university hospital, divided into 30 females with malignant breast lesion and 20 healthy females as a control group. Colorimetric assay of serum levels of NO, MDA and TAO, while, sFas was determined using ELISA method.

Results: There were significant high levels of NO, MDA, TAO and sFas in malignant group than in control group with p-value < 0.0001 , high positive correlation between NO, MDA, TAO and sFas in malignant group $(\mathrm{r}=0.958,0.807,0.748$ respectively and $\mathrm{P}<0.0001$ for all). There was high positive correlation between NO and TAO in malignant group $(\mathrm{r}=0.78, \mathrm{P}<0.0001)$. There was also, high positive correlation between MDA and TAO in malignant group $(\mathrm{r}=0.81, \mathrm{P}<0.0001)$.

Conclusion: These results support the oxidative stress hypothesis and resistance to apoptosis in development and progression of breast cancer.
\end{abstract}

Keywords: Breast Cancer; Egyptian Females; Oxidative Stress; Soluble Fas.

\section{Introduction}

Breast cancer is the second most common cancer in the world. Approximately every tenth cancer diagnosed worldwide is a breast cancer. Breast cancer is also the most common cancer and the most common cause of cancer death among women worldwide [1]. The ancient Egyptians were the first civilization to document clinical cases of breast cancer, as shown on papyrus paper dated 1600 BC "The Edwin Smith Papyrus" found in Thebes in 1862 until translated in 1930 describing a case of very cool bulging tumours of the breast, on touch, with no fever, granulation, or fluid secretion and mentioning that, there are no treatment[23]..Breast cancer cancer represents a serious health problem and is currently the most frequent malignancy in female population. According to the National Cancer Institute, Cairo, Egypt, breast cancer is the first most common malignancy in Egyptian females[4].

Usually, breast cancer is discovered before any symptoms are present, either on mammography or by feeling a breast lump. Possible symptoms include breast discharge, nipple inversion and changes in the skin overlying the breast. Screening methods suggested include breast self-examination and mammography[5-
6].The The diagnosis of breast cancer is established by the pathological examination of removed breast tissue. Such tissue is generally obtained at the time of surgical treatment. A number of procedures have been devised to obtain tissue or cells prior to the treatment for histological or cytological examination. Such procedures include fine-needle aspiration, nipples aspirates, ductal lavage, core needle biopsy, and local surgical biopsy. Imaging tests are used to detect metastasis and they include chest x-ray, bone scan, CT, MRI, and PET (Positron emission tomography) scanning [68].

Oxidative stress is considered to be involved in the pathophysiology of every cancers [9], especially breast cancer [10]. Oxidative stress caused by increased free radical generation and/or decreased antioxidant level in the target cells and tissues has been suggested to play an important role in carcinogenesis [11].Free Free radicals are capable of altering all major classes of biomolecules, such as lipids, nucleic acids and proteins, with changes in their structure and function [12].The The term "free radicals" designates a family of compounds characterized by great reactivity due to the unpaired electron in the outer orbital. To this group belong reactive oxygen species (ROS), such as super oxide anion, hydroxyl radical and hydrogen peroxide, as well as reactive nitrogen species (RNS) which include nitric oxide and peroxynitrite. They are mainly 
involved in DNA damage leading sometimes to mutations in tumor suppressor genes. They also act as initiator and/or promotor in carcinogenesis [12].

Prime targets of free radicals are the polyunsaturated fatty acids in cell membranes and their interaction results in lipid peroxidation [13].MalondialdehydeMalondialdehyde "MDA" is a lowmolecular weight aldehyde that can be produced from free radical attack on polyunsaturated fatty acids. It is used as a marker of oxidative stress, there has been a growing interest in studying the role played by lipid peroxidation in cancer progression [14].MDA MDA is said to be involved in DNA adduct formations, which are believed to be responsible for carcinogenesis [13-15].

Nitric oxide $\left(\mathrm{NO}^{\circ}\right)$ is an intra- and extracellular messenger that mediates diverse signaling pathways in target cells and is known to play an important role in many physiological processes including neuronal signaling, immune response, inflammatory response, modulation of ion channels and phagocytic defense mechanism [16].It was found that $\mathrm{NO}^{*}$ has a controversial effect on apoptosis [17].This controversial effect was obvious in human breast cancer, where at low concentration it increases proliferation by increasing synthesis of some cells cycle protein and in higher concentrations it leads to apoptosis by decreasing translation of some cell cycle proteins [18].

The physiological defense systems to counteract free radicals encompass endogenous enzyme systems, such as catalase, glutathione reductase and superoxide dismutase, as well as glutathione and coenzyme $\mathrm{Q}$, or exogenous factors $(\beta$-carotene, vitamin $\mathrm{C}$ vitamin $\mathrm{E}$ and selenium). All these molecules have an antioxidant effect due to their ability to transform ROS into stable and harmless compounds or by scavenging both ROS and RNS with a redox-based mechanism [19].

Apoptosis is the most common mechanism by which the body eliminates damaged or unneeded cells without local inflammation from leakage of cell contents [20]. Dysregulation of apoptosis is implicated in a variety of diseases states. Accelerated cell death is implicated in the pathogenesis of a number of diseases, including neurodegenerative diseases such as Alzheimer's disease and acquired immunodeficiency syndrome. Conversely, an inappropriately low rate of apoptosis can give rise to cancer or autoimmune disorders [20].

Apoptosis occurs via two main signaling pathways; the intrinsic and the extrinsic pathways [21].The intrinsic pathwayis triggered from within the cell by developmental cues or severe cell stress, such as DNA damage. The extrinsic pathway is activated when a pro-apoptotic ligand, such as endogenous Fas ligand or APO2 ligand/tumor necrosis factor (TNF)-related apoptosis-inducing ligand (Apo2L/TRAIL), binds to pro-apoptotic receptors, such as Fas, or DR4 and DR5. Destruction of the cell is ultimately carried out by intracellular protease enzymes called caspases that, on activation through the intrinsic and/or extrinsic pathways, destroy cellular proteins that are vital for cell survival [22].Cancer, another leading cause of mortality, arises from neoplastic progression through avoidance of apoptosis[23].In addition, dysregulation of Fas/FasL mediated apoptosis can contribute to the pathogenesis of neoplastic fibrosis [24].

Fas (APO-1 / CD95) is a transmembrane receptor that belongs to the TNF/ nerve growth factor (NGF) receptor family (type, I membrane protein), and is widely expressed on normal and malignant cells [25-29]. Fas can occur as both a cell- surface (Fas) and a soluble protein (sFas). sFas is generated by alternative mRNA splicing [30-31], and lacks a trans membrane domain, is thought to inhibit Fas-FasL binding and block sFas-mediated apoptosis [3235].The The Fas ligand (Fas-L) is a membrane-bound cytokine and a member of the TNF family (type II membrane protein) [2527,36].Fas-L can be processed to a soluble form (sFas-L) by a metalloproteinase like TNF [37-38].Sensitive Sensitive cells that express Fas undergo apoptosis upon contact with Fas-L or agonistic, cross-linking antibodies, indicating that Fas-L is a death factor and that Fas is its receptor. Pathologically, the Fas-Fas ligand system is involved in eliminating autoreactive immune cells, malignant cells, or virally infected cells [25-27]. All variants of sFas inhibit apoptosis induced by FasL [39-40].Serum sFas levels increased with increasing stages of breast cancer. Thus, subjects with cancer have higher anti-apoptotic factors ( $\mathrm{sFas}$ ) in circulation and less proapoptotic factors (sFasL, cytochrome c) in circulation. Also, the more advanced the cancer, the larger the change in circulating levels [41].The The clinical significance of serum sFas levels has not yet been clarified. The molecular mechanisms underlying resistance to apoptosis mediated by the Fas-FasL system are complex and involve both postreceptor and prereceptor events [42-43].PrereceptorPrereceptor resistance can be mediated by sFas, which antagonizes both anti-Fas and FasL-mediated cell lysis in a dose-dependent manner [39, 42-44].Because a loss of Fas function has been implicated in the pathogenesis of tumor progression, the production of sFas may be involved in the pathogenesis of malignant disease [44].

\section{Patients and methods}

\subsection{Study population and matched controls}

A cross-sectional case/control study conducted on 50 Egyptian females divided into two groups: Group A involves 30 females with malignant breast lesion were pathologically diagnosed as infiltrating ductal carcinoma (median age 55 years old, age range 39- 81years). Group B involves 20 apparently healthy females as a control group (median age 50 years old, age range $38-65$ years). They were recruited from outpatient clinics or admitted to inpatients department of the general surgery at Sohag university hospital, Upper Egypt, after approval of the university hospital ethical committee and after taking written consent from every subject involved in this study. The study was carried out during the period from May 2013 to July 2015.

\subsection{Biochemical assessments of serum levels of sFas, NO, MDA, TAO}

From all cases and control subjects $6 \mathrm{ml}$ venous blood samples were collected without using an anticoagulant by vacutainer system under complete aseptic conditions, Allow blood to clot for 30 min. at $25^{\circ} \mathrm{C}$. Centrifuge the blood at $3000 \mathrm{rpm}$ for $15 \mathrm{~min}$. pipette off the top yellow serum layer without disturbing the white buffy layer. Serum samples were stored at $-80^{\circ} \mathrm{C}$.Using commercially available assay kit according to manufacturer protocol for measurements of:

1) Serum sAPO-1/Fas (Bender MedSystems, Austria) [using enzyme-linked immune-sorbent assay (ELISA) multiskan EX microplatephotomter, thermo scientific, STAT FAX2100, USA].

2) Colorimetric assay- using T60 UV visible spectrophotometer. PG INSTRUMENTS LIMITED, Alma park wibtoft, Leicester shreshire, England. LE17SBE. Serial No. 201650-01-0010- for each of the following oxidants and antioxidants biochemical markers:

a) Nitric oxide (Biodiagnostics, Cairo, Egypt), (by an endpoint enzymatic one-step assay with nitrate reductase).

b) Malondialdehyde"MDA": an end product of lipid peroxidation of erythrocytes can react with thiobarbituric acid (TBA) to form a colored complex called thiobarbituric acid reactive substance (TBARS) by using a diagnostic kit supplied by Biodiagnostic, Cairo, Egypt.

c) Total antioxidant capacity "TAC" (Biodiagnostics, Cairo, Egypt) by using a diagnostic kit supplied by Biodiagnostic, Cairo, Egypt. The determination of the antioxidative capacity is performed by the reaction of antioxidants in the sample with a defined amount of exogenously provide hydrogen peroxide $\left(\mathrm{H}_{2} \mathrm{O}_{2}\right)$. The antioxidants in the sample eliminate a certain amount of the provided hydrogen peroxide. The residual $\mathrm{H} 2 \mathrm{O} 2$ is determined calorimetrically by an enzymatic reaction which involves the conversion of 3,5 , dichloro -2 hydroxyl benzene sulphonate to a colored product. 


\subsection{Statistical analysis}

Values are given as means \pm standard error (SED). Correlation coefficients were used to describe associations between variables. $\mathrm{P}<0.05$ was considered significant. Analyses were performed using the SPSS software package (SPSS V 17 for Windows).

\section{Results}

The comparison between mean circulating levels of investigated laboratory parameters in control and malignant groups are presented in Table 1, with statistically significant high levels of NO, MDA, TAO and sFas in malignant group than in control group with $p$-value $<0.0001$ for all laboratory parameters.

Table 1: Comparison between Mean Circulating Levels of Investigated Laboratory Parameters in Control and Malignant Groups

\begin{tabular}{llll}
\hline Laboratory parameters & Control N=20 & $\begin{array}{l}\text { Malignant } \\
\mathrm{N}=30\end{array}$ & P value \\
\hline NO(mean \pm SED, & $3.523 \pm$ & $53.2 \pm 1.420$ & $<0.0001$ *** \\
$\mathrm{nmol} / \mathrm{ml})$ & 0.3149 & $4.553 \pm$ & $<$ \\
$\mathrm{MDA}(\mathrm{mean} \pm$ & $0.1145 \pm$ & 0.1821 & $0.0001 * * *$ \\
$\mathrm{SED}, \mathrm{nmol} / \mathrm{ml})$ & 0.009692 & $0.6617 \pm$ & $<$ \\
$\mathrm{TAO}(\mathrm{mean} \pm \mathrm{SED}$, & $0.140 \pm$ & 0.018 & $0.0001 * * *$ \\
$\mathrm{nmol} / \mathrm{ml})$ & 0.0136 & $243.9 \pm 19.77$ & $<.0001 * * *$ \\
sFas $(\mathrm{mean} \pm$ & $108.8 \pm 7.578$ & & \\
SED,pg/ml) & & & \\
\hline
\end{tabular}

There were high positive correlations between NO, MDA, TAO and $\mathrm{sFas}$ in malignant group $(\mathrm{r}=0.958,0.807,0.748$ respectively and $\mathrm{P}<0.0001$ for all). Fig. 1, 2, 3 .

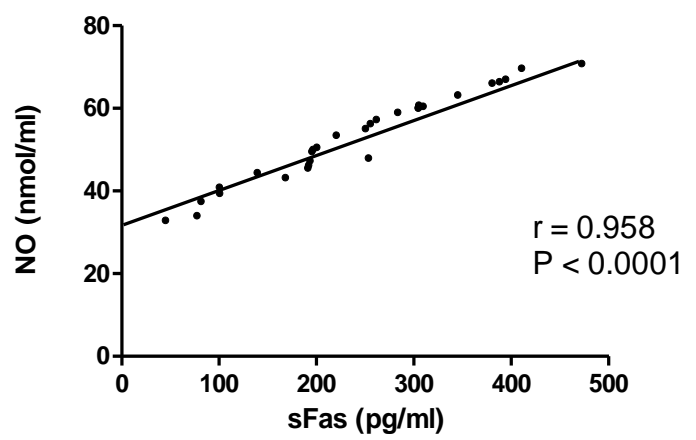

Fig. 1:Correlation between NO and Sfas in Malignant Group.

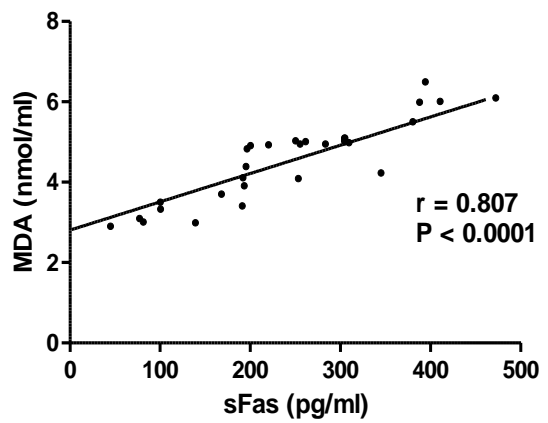

Fig. 2:Correlation between MDA and Sfas in Malignant Group.

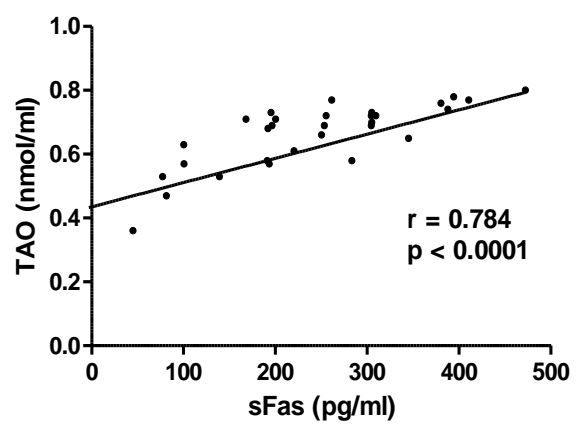

Fig. 3:Correlation between TAO and Sfas in Malignant Group.
Also there was high positive correlation between $\mathrm{NO}$ and TAO in malignant group $(\mathrm{r}=0.78, \mathrm{P}<0.0001)$. Fig. 4 . High positive correlation between MDA and TAO in malignant group $(\mathrm{r}=0.81, \mathrm{P}<$ 0.0001).Fig.5

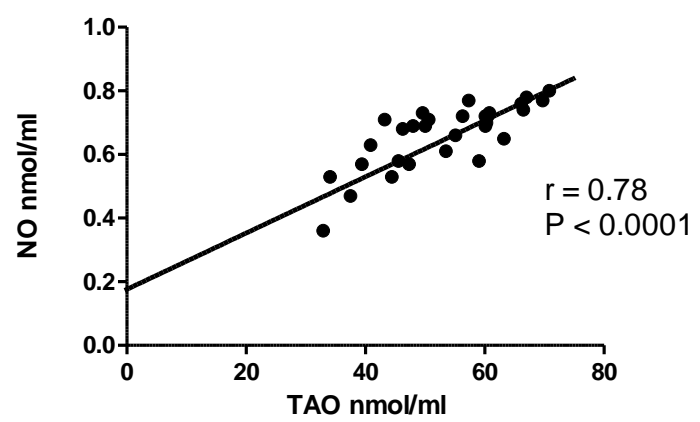

Fig. 4:Correlation between TAO and NO in Malignant Group.

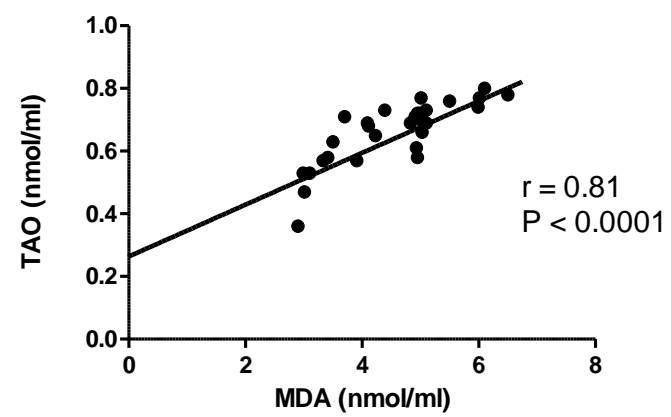

Fig. 5:Correlation between TAO and MDA in Malignant Group.

\section{Discussion}

In order to develop an effective strategy to prevent and treat certain disorders, an accurate evaluation of ROS and antioxidants has a critical importance, The purpose of the present study was to evaluate ROS and NO in the pathogenesis of breast cancer and correlate them with apoptosis in infiltrating ductal carcinoma, which is popular pathological breast cancer among Egyptian female patients [45].

In the present study, there were statistically significant higher serum MDA levels in breast cancer group than in control group (p-value $<0.0001$ ) as shown in Table 1. In agreement with this finding, Aghvami et al [11], reported that MDA level increased significantly in breast cancer patients when compared to the controls. Regarding the serum levels of NO, there was statistically higher serum NO levels in breast cancer group than in control group (p-value $<0.0001$ ) as shown in Table 1. This results support the general observation that some malignancies are associated with an increased level of nitric oxide. As reported by a study done by Ray et al [46], conducted on breast cancer patients, who showed that patients with stage two disease have the highest levels of NO compared to controls. Farag et al [45], founda significant correlation between MDA, NO and higher histological grade as well as with advanced tumor stage of breast cancer. This indicates that increased MDA and NO give the transformed cells a selective growth advantage.

In studies that were carried out in order to investigate the role of antioxidants in cancer, antioxidants were measured separately; but owing to the various total effects of antioxidants, measuring the total effects of antioxidants " TAO" can provide more accurate results [46].In contrast to Sener et al [13] who reported that total antioxidant capacity was decreased in cancerous patients, our study showed a relatively higher TAO in malignant patients compared to control group $(\mathrm{p}<0.0001)$ as shown in Table 1 with significant positive correlation with NO level $(\mathrm{P}<0.0001)$ (Fig.4) and MDA level $(\mathrm{P}<0.0001)$ (Fig.5). The higher TAO activities in our study may be due to the response of increased ROS production 
and excessive antioxidant consumption with inability to detoxify high levels of $\mathrm{H}_{2} \mathrm{O}_{2}$ into $\mathrm{H}_{2} \mathrm{O}$ that results in the formation of the most dangerous $\mathrm{OH}^{-}$radical followed by MDA and development of oxidative stress. This finding was in agreement with Gönenc et al [47], who investigated 15 breast cancer cases and 15 controls and showed that TAO level, was elevated in the breast cancer patient group compared to control group.

The apoptotic profile in our study was also investigated by estimation of circulating levels of sFas "as inhibitor of apoptosis". It showed significantly higher levels in breast cancer group when compared to control group, $\mathrm{p}<0.0001$ (Table 1). This finding was agreed with a study done by Nassar et al [48], who compare the serum levels of sFas in normal females with those of invasive breast carcinoma and found that sFas was generally higher in invasive breast cancer. It has been reported that serum soluble Fas may play a role in the pathogenesis of cancers through down regulation of Fas-mediated apoptosis of activated lymphocytes and tumor cells [49].

Also higher significant increase of MDA, NO, TAO and sFas showed in malignant group compared to control groups $(\mathrm{P}<0.0001)$ found in the present study are similarly to Pervin et al [18], who demonstrate that both oxidative stress and apoptosis was correlated strongly with tissues cancers.

Also, serum sFas level showed highly significant positive correlation with NO level $(\mathrm{P}<0.0001)$ (Fig.1) and MDA level $(\mathrm{P}<0.0001)$ (Fig.2). Since tumorigenesis is associated with a resistance to apoptosis, increased activity of sFas in malignant group compared to control group may be due to associated significant increased levels of NO, MDA in malignant groups, which are considered as pro-apoptotic stimulatory factors. This finding would appear to be in agreement with the widely held belief that apoptosis is reduced in malignancy. So this explain the highly significant positive correlation of serum sFas level with TAO level ( $\mathrm{P}<0.0001)$ (Fig.3), as both antagonize the increased levels of free radicals (NO and MDA) with different pathways.

\section{Conclusions}

The results of this study support the oxidative stress hypothesis and resistance to apoptosis in development and progression of breast cancer. Therefore, administration of antioxidant drugs may be helpful in the management of breast cancer patients. The regulation of intracellular ROS levels by drugs may represent one possibility to normalize the dysregulated apoptosis in tumor cells.

\section{Conflict of interest}

The authors declare that there is no conflict of interests regarding the publication of this article.

\section{References}

[1] J. Ferlay, D.M. Parkin, E. Steliarova-Foucher. Estimates of cancer incidence and mortality in Europe in 2008. European Journal of Cancer, $\quad 46 \quad$ (2010) 765-781. http://dx.doi.org/10.1016/j.ejca.2009.12.014

[2] J.H. Breasted, Edwin Smith Surgical Papyrus. The University of Chicago Press, Illinois. Coated from Ebeid NI.; Surgery Chapter 5 in: Egyptian Medicine in the Days of the Pharaohs. The General Egyptian Book Organization, 1999; 403-406.

[3] A.S. Ibrahim, Epidemiology of breast Cancer. Editors: G .Contesse, S.Omar. Breast cancer. The Cairo Medical Syndicate Scientific Committee; 1984: 1-13.

[4] A. S. Ibrahim, H. M. Khaled, N. N.H Mikhail, H. Baraka, H. Kamel. Cancer incidence in Egypt: results of the national population-based cancer registry program. Journal of Cancer Epidemiology, 2014 (2014)1-18.http://dx.doi.org/10.1155/2014/437971.

[5] J. M. Elwood, B. Cox, A.K. Richardson. The effectiveness of breast cancer screening by mammography in younger women. Online $J$ CurrClin Trials, 1 (1993) 32-227.
[6] G.N. Hortobagyi, L.Esserman, T.A.Buchholz. Neoplasms of the Breast. In: Kufe DW, Bast RC, Hait WN, et al, eds. Cancer Medicine. 7th ed. Hamilton, Ontario: BC Decker, 2006; 1584-1643.

[7] M. Morrow. Magnetic resonance imaging in breast cancer: one step forward, tow steps back? The Journal of the American Medical Association, $292 \quad$ (2004) 80.http://dx.doi.org/10.1001/jama.292.22.2779.

[8] N. Hylton. Magnetic resonance imaging of breast: Opportunities to improve breast cancer management. Journal of Clinical Oncology 23 (2005)1678-84.http://dx.doi.org/10.1200/JCO.2005.12.002.

[9] J.C.Reed, M. Pellecchi. Apoptosis-based therapies for hematologic malignancies. Blood, 106 (2005) 408418.http://dx.doi.org/10.1182/blood-2004-07-2761.

[10] J. Zipprich, M.B.Terry, Y.Liao, M. Agrawal, I. Gurvich, R.Senie, R.M. Santella. Plasma protein carbonyls and breast cancer risk in sisters discordant for breast cancer from the New York site of the breast cancer family registry. Cancer Res, 69 (2009) 296672.http://dx.doi.org/10.1158/0008-5472.CAN-08-3418.

[11] T. Aghvami, M. Djalali, A. Keshavarz, M.R. Sadeghi, H. Zeraati,H.S.Yeganeh, M. Negahdar. Plasma level of antioxidant vitamins and lipid peroxidation in breast cancer patients. Iranian $J$ Publ Health, 35(2006) 42-47.

[12] E.K. Pauwels, P.A.Erba, M. Kostkiewicz. Antioxidants: A tale of two stories. Drug News Perspect, $20 \quad$ (2007) 579 585.http://dx.doi.org/10.1358/dnp.2007.20.9.1162242.

[13] D.E. Sener, A. Gonenc, M. Akinci, M. Torun. Lipid peroxidation and total antioxidant status in patients with breast cancer. Cell BiochemFunct, 25(2007) 82.http://dx.doi.org/10.1002/cbf.1308.

[14] J.L. do Val Carneiro, S.L.Nixdorf, M.S. Mantovani, H.A.C. da Silva do Amaral, M.N. Aoki, M.K. Amarante, B.A. Fabris, F.M.H Pelegrinelli, W.M.A. Ehara. Plasma malondialdehyde levels and CXCR4 expression in peripheral blood cells of breast cancer patients. J Cancer Res ClinOncol, $135 \quad$ (2009) $997-$ 1004.http://dx.doi.org/10.1007/s00432-008-0535-7.

[15] G. Ray, S.A. Husain. Oxidants, antioxidants and carcinogenesis. Indian J ExpBiol, 40(2002) 1213-32.

[16] N. Tuteja , M.Chandra, R. Tuteja , M.K. Misra . Nitric Oxide as a Unique Bioactive Signaling Messenger in Physiology and Pathophysiology.J Biomed Biotechnol, 4(2004): 227 237.http://dx.doi.org/10.1155/S1110724304402034.

[17] B. Brüne, A. von Knethen, K.B.Sandau. Nitric oxide (NO): an effector of apoptosis. Cell Death Differ, 6 (1999) 96975.http://dx.doi.org/10.1038/sj.cdd.4400582.

[18] S. Pervin, R. Singh, G. Chaudhuri. Nitric oxide, N omegahydroxy-L-arginine and breast cancer. Nitric Oxide, 19 (2008)1036.http://dx.doi.org/10.1016/j.niox.2008.04.016.

[19] M. Valko, C.J. Rhodes, J. Moncol, M. Izakovic, M. Mazur. Free radicals, metals and antioxidants in oxidative stress-induced cancer. ChemBiol Interact, 160 (2006)1-40 http://dx.doi.org/10.1016/j.cbi.2005.12.009.

[20] B. Fadeel, S. Orrenius. Apoptosis: a basic biological phenomenon with wide-ranging implications in human disease. J Intern Med, 258 (2005) 479-517.http://dx.doi.org/10.1111/j.13652796.2005.01570.x.

[21] S. Fulda, K.M. Debatin. Extrinsic versus intrinsic apoptosis pathways in anticancer chemotherapy. Oncogene, 25(2006) 4798811.http://dx.doi.org/10.1038/sj.onc.1209608.

[22] I.N. Lavrik, A. Golks, P.H. Krammer. Caspases: pharmacological manipulation of cell death. J Clin Invest, 115(2005) 26652672.http://dx.doi.org/10.1172/JCI26252.

[23] M. Villa-Morales, J. Fernández-Piqueras. Targeting the Fas/FasL signaling pathway in cancer therapy.Expert Opin Ther Targets, 16(2012)85-101 .http://dx.doi.org/10.1517/14728222.2011.628937.

[24] Z.Peng, Y.Zhang, W.Gu, Z.Wang, D.Li, F.Zhang, G.Qiu, K.Xie. Int egra-

tion of the hepatitis B virus X fragment in hepatocellular carcinoma and its effects on the expression of multiple molecules: a key to the cell cycle and apoptosis. Int J Oncol, 26 (2005) 467-473

[25] S. Nagata, P. Golstein. The Fas death factor [review]. Science, 267 (1995) 1449-1456.http://dx.doi.org/10.1126/science.7533326.

[26] C.A.Smith, T. Farrah, R.G.Goodwin. The TNF receptor superfamily of cellular and viral proteins: activation, co stimulation, and death. Cell, 76(1994) 959-962.http://dx.doi.org/10.1016/0092 8674(94)90372-7.

[27] S. Nagata. Apoptosis by death factor. Cell, 88 (1997)355365.http://dx.doi.org/10.1016/S0092-8674(00)81874-7.

[28] R. Watanabe-Fukunaga, C.I. Brannan, N. Itoh, et al. The cDNA structure, expression, and chromosomal assignment of the mouse Fas antigen. J Immunol, 148 (1992)1274-1279. 
[29] E. Leitha, F. user, J. Dhein, G. Mechtersheimer, et al. Constitutive and induced expression of APO-1, a new member of the nerve growth factor/tumor necrosis factor receptor superfamily, in normal and neoplastic cells. Lab Invest, 69(1993) 415-429.

[30] J.Cheng, T.Zhou, C.Liu, J.P.Shapiro, M.J.Brauer, M.C.Kiefer, P.J. Barr, J.D. Mountz. Protection from Fas-mediated apoptosis by asoluble form of the Fas molecule. $S$ cience, 263 1762.http://dx.doi.org/10.1126/science.7510905.

[31] I. Cascino, G. Fiucci, G. Papoff, G. Ruberti. Three functional soluble forms of the human apoptosis-inducing Fas molecule are produced by alternative splicing. J Immunol, 154 (1995) 2706-2713.

[32] S.L.B. Owen, L.S. Angelo, R. Radinsky, C.F. Ware, T.G. Gesner, D.P. Bartos. Soluble Fas/APO1 in tumor cells: a potential regulator of apoptosis? .Cancer Lett, $94 \quad$ (1995)18.http://dx.doi.org/10.1016/0304-3835(95)03834-J.

[33] I. Cascino, G. Fiucci, G. Papoff, G. Ruberti. Three functional soluble forms of the human apoptosis inducing Fas molecule are produced by alternative splicing. J.Immunol , 154 (1995) 2706-2713.

[34] G. Natoli , A. Innai , A. Costanzo , G. De Petrillo , I. Ilai , C. Chirillo, C. Balsano, M. Levero. Resistance to Fas mediated apoptosis in human hepatoma cells. Oncogene, 10 (1995) 1157-1164.

[35] T. Suda, T. Takahahi, P. Golstein, S. Nagata. Molecular cloning and expression of the Fas ligand, a novel member of the tumor necrosis factor family. Cell, 75(1993)11691178.http://dx.doi.org/10.1016/0092-8674(93)90326-L.

[36] N. Kayagaki, A. Kawasaki, T. Ebata, et al. Metallo-proteinase mediated release of human Fas ligand. J Exp Med, 182 (1995)17771783.http://dx.doi.org/10.1084/jem.182.6.1777.

[37] M. Tanaka, T. Suda, T. Takahashi, S. Nagata. Expression of the functional soluble form of human Fas ligand inactivated lymphocytes. EMBO J, 14 (1995) 1129-1135.

[38] G.Papoff, I.Cascino,

A. Eramo, G.Starace G, D.H.Lynch, G.Ruberti. An N-terminal d omain shared by Fas/Apo-1 (CD95) soluble variants prevents cell d eath invitro. J Immunol, 156 (1996) 4622-4630.

[39] .N. Kavathia, A. Jain, J. Walston, A.B. Beamer, S.N. Fedarko.Serum markers of apoptosis decrease with age and cancer stage. $\begin{array}{llll}J & A G I N G, & 1 & \text { (2009) }\end{array}$ 663.http://dx.doi.org/10.18632/aging.100069.

[40] S. Nagata. Fas and Fas ligand: a death factor and its receptor Adv.Immunol, 57 (1994)12-144.http://dx.doi.org/10.1016/S0065 2776(08)60672-0.

[41] T. Sato,S. Irie, S. Kitada, J.C.Reed. FAP1: a protein tyrosine phosphatase that associates with Fas. Science, 268 (1995)411415.http://dx.doi.org/10.1126/science.7536343.

[42] G. Natoli, A. Innai, A. Costanzo, G. DePetrillo, I. Ilai, C. Chirillo, C. Balsano, M. Levero. Resistance to Fas mediated apoptosis in human hepatoma cells. Oncogene, 10 (1995)1157-1164.

[43] M. Zornig, A. Grzeschizek, M.B. Kowalsky, K.U. Hartmann, T. Moroy. Loss of Fas/APO-1 receptor accelerates lymphoma-genesis in EmL-MYC transgenic mice but not in animals infected with Mo MuLV. Oncogene, 10(1995) 2397-2401.

[44] M.I. Othman, M.I. Majid, M. Singh, S. Subathra, L. Seng, L.H Gam. Proteomics of Grade 3 infiltrating ductal carcinoma in Malaysian Chinese breast cancer patients. BiotechnolApplBiochem, 52(2009) 209-19.http://dx.doi.org/10.1042/BA20070271.

[45] R. Farag, M. Ahmed, M. El-Gendy, I. Mohamed. Evaluation of oxidative stress and apoptosis in breast cancer. Egyptien Journal of Biochemistry and Molecular Biology, 27(2009) 63-82.

[46] G.N. Ray, M. Shahid, S.A. Husain. Effect of nitric oxide and malondialdehyde on sister-chromatid exchanges in breast cancer. Br J Biomed Sci 58 (2001) 169-76.

[47] A. Gönenç, D. Erten, S. Aslan, M. Akinci, B. Simşek, M. Torun. Lipid peroxidation and antioxidant status in blood and tissue of malignant breast tumor and benign breast disease. Cell BiolInt, 30 (2006) 376-80.http://dx.doi.org/10.1016/j.cellbi.2006.02.005

[48] A. Nassar, D. Lawson, G. Cotsonis, C. Cohen. Survivin and caspase-3 expression in breast cancer: correlation with prognostic parameters, proliferation, angiogenesis, and outcome. ApplImmunohistochemMolMorphol, $16 \quad$ (2008) 113 20.http://dx.doi.org/10.1097/PAI.0b013e318032ea73.

[49] A. Ates, G. Kihikli, M. Turgay, N. Duman. The levels of serum-soluble Fas in patients with rheumatoid arthritis and systemic sclerosis, Clin. Rheumatol, 23 (2004) 421425.http://dx.doi.org/10.1007/s10067-004-0909-4. 